Neuropsychobiology 2006;54:114-119

DOI: $10.1159 / 000098261$
Received: December 2, 2005

Accepted after revision: September 29, 2006

Published online: January 3, 2007

\title{
Facial Expressions and Personality: A Kinematical Investigation during an Emotion Induction Experiment
}

\author{
Roland Mergl $^{\mathrm{a}}$ Michael Vogel ${ }^{\mathrm{a}}$ Anuschka Prässl ${ }^{\mathrm{a}}$ Birgit Graf ${ }^{\mathrm{a}}$ Max Karner ${ }^{\mathrm{a}}$ \\ Paraskevi Mavrogiorgou $^{b} \quad$ Ulrich Hegerl $^{\mathrm{a}}$ Georg Juckel ${ }^{\mathrm{b}}$ \\ Departments of Psychiatry, ${ }^{a}$ Laboratory of Clinical Neurophysiology, Ludwig Maximilians University Munich, Munich, \\ and ${ }^{b}$ Westfälisches Zentrum Bochum, Ruhr University Bochum, Bochum, Germany
}

\section{Key Words}

Personality - Facial expression - Kinematic analysis •

NEO Five-Factor Inventory · Sensation seeking

\begin{abstract}
Background/Aims: In order to elucidate the relationship between personality traits and expression of positive emotions in healthy volunteers, standardized personality inventories and kinematical analysis of facial expressions can be helpful and were applied in the present study. Methods: Markers fixed at distinct points of the face emitting ultrasonic signals at high frequency gave a direct measure of facial movements with high spatial-temporal resolution. Forty-six healthy participants (mean age: 40.7 years; 20 males, 26 females) watching a witty movie ('Mr. Bean') were investigated. Results: Speed of 'laughing' was associated with higher scores on Zuckerman's Sensation Seeking Scale and NEO-FFI (Openness to Experience). Conclusion: Kinematical analysis of facial expressions seems to reflect sensation seeking and related personality styles. Higher speed of facial movements in sensation seekers suggests lowered serotonergic function.

Copyright $\odot 2006$ S. Karger AG, Basel
\end{abstract}

\section{Introduction}

Facial expressions represent a basic component of human emotional behavior [1]. So far, only few studies examined the association between distinct personality traits and facial expression of emotional states. This is surprising because there are considerable individual differences in facial expression of emotions across healthy volunteers as well as patients sharing the same diagnosis [2]. The perception of facial expression of emotions is dependent on personality traits, too. So, Niedenthal et al. [3] could demonstrate strong effects of attachment orientation on the perception of emotional stimuli: under normal conditions (absent distress), fearfully attached subjects noticed the offset of happiness and anger in computerized movies of faces earlier, and dismissive subjects later, than securely attached persons.

The ability to encode basic emotions is very closely associated with basic aspects of personality [4]. Several studies [e.g., ref. 5, 6] suggest that two personality traits - dominance (governing, controlling) and exhibition (entertaining) - represent important personality correlates of emotional encoding abilities. Regarding more spontaneous emotional expression, encoding ability seems to be closely tied to extraversion and nonverbal emotional expressiveness.

\section{KARGER \\ Fax +41613061234 E-Mail karger@karger.ch} www.karger.com
Dr. Dipl.-Psych. Roland Mergl

Department of Psychiatry, Ludwig-Maximilians-Universität München

Nussbaumstrasse 7, DE-80336 München (Germany)

Tel. +49 895160 5558, Fax +498951605542

E-Mail Roland.Mergl@med.uni-muenchen.de 
In view of these promising findings, we wanted to investigate facial movements elicited by emotional stimuli in healthy participants with different personality styles, using a kinematical approach. Computer-aided measurement of facial expression of emotions represents a methodological advance since it can be utilized for the exact measurement of the initial velocity of laughing movements elicited by emotional (humorous) stimuli [7-9]. Moreover, this method is a sensitive tool to investigate hypomimia in patients with depression [10] or obsessivecompulsive disorder [11].

The main aim of this study was to answer the question whether facial expression as assessed during an emotioninducing experiment might be related to distinct personality traits, especially extraversion.

\section{Method}

\section{Participants}

The study was approved by the local Ethics Committee and performed in accordance with the ethical standards laid down in the 1964 Declaration of Helsinki [12]. It was conducted in 46 healthy volunteers, who gave their written informed consent prior to their inclusion in the study. The healthy volunteers did not receive any financial compensation for participating in the study. All participants had normal or corrected-to-normal vision. Inclusion criteria required absence of psychotropic drugs and mental disorders (according to ICD-10 criteria [13]). The subjects (20 male, 26 female; all right-handers) had a mean age of 40.70 years (SD 13.93 years) and were 12.07 years (SD 1.49 years) at school. Their mean 'mood' score on a visual analog scale (VAS) was 1.23 (SD 1.21) and their VAS 'funniness of movie’ score 10.73 (SD 3.40).

\section{Personality Measures}

The participants completed a German version of the Zuckerman Sensation Seeking Scale (SSS, form V, a 40-item self-report) [14]. This highly reproducible questionnaire [15] aims to assess sensation seeking by evaluating four factors which contribute to this construct [16]. The dimensions of sensation seeking - with ten questions of the SSS relating to each factor - are as follows: Thrill and Adventure Seeking (willingness to participate in activities which are known to be physically risky); Experience Seeking (willingness to seek novel sensations and experiences, e.g. music, arts); Disinhibition (seeking sensations in activities like sex and parties), and Boredom Susceptibility (regarding repetitive routine work).

The SSS items are dichotomous. Therefore, a score of 1 was assigned if the sensation-seeking response was positive and a score of 0 if it was negative. For each respondent, total sum scores and factor-specific sum scores were computed. Normative data for a German version of the SSS are available from a large sample $(1,526$ subjects; 823 female) [17]. Internal consistency (Cronbach's alpha) of the SSS total score was sufficient (0.82) in the normative sample. Using an exploratory factor analysis, the four-factor structure of the SSS could be confirmed.

Facial Expressions and Personality
Moreover, personality of the healthy volunteers was assessed using the NEO Five-Factor Inventory (NEO-FFI) [18], a 60-item self-report designed to measure the five-factor model of personality traits [19], which is considered to provide an optimal representation of personality [e.g., ref. 20]. The personality dimensions assessed by the NEO-FFI are as follows: Neuroticism versus Emotional Stability, Extraversion, Openness to Experience, Agreeableness versus Antagonism, Conscientiousness or Will to Achieve.

The NEO-FFI contains 12 items which assess each of these five personality traits. Scores for each item range from 0 to 4 . Total scores for each trait were computed as follows: sum scores for each trait (range: $0-48$ )/number of items (12). Normative data for the NEO-FFI are derived from a large sample (over 2,100 men and women) [21]. Internal consistency of the five personality scales was between 0.71 and 0.85 in the normative sample.

\section{Kinematical Analysis of Facial Expression}

We used an active device for the three-dimensional measurement of movements (CMS 70; ZEBRIS Ltd., Tübingen, Germany) to analyze facial movements elicited by humorous stimuli in a movie [for details see ref. 9].

High-frequency ultrasonic signals were emitted by ultrasonic markers and registered online (sampling rate: $200 \mathrm{~Hz}$ divided by the number of ultrasonic markers). One reference marker was fixed to the forehead, two markers to the mouth angles in order to measure activity of the zygomatic major and minor, risorius and depressor anguli oris muscles, two other markers to the medial inferior rims of the eyes in order to register activity of the orbicularis oculi muscle. All these muscles are innervated by the nervus facialis.

In a quiet room, the healthy participants were individually seated in front of a device for registration of ultrasonic signals, a video camera and a television screen (in order to present one ' $\mathrm{Mr}$. Bean' sketch). The participants assessed how funny the sketch was, applying a VAS (minimum value: $0 \mathrm{~mm}$; maximal value: $167 \mathrm{~mm}$ ).

Facial activity was registered by applying an ultrasonic measurement system and simultaneous video-recording of the face. The sketch, video-recording and facial activity were synchronized applying a frame code generator.

Using 3DA software, the digitalized signals of the ultrasonic markers were filtered using a special algorithm [22]. 'Laughing' was evaluated in five film sequences previously assessed as being especially funny by identifying synchronous changes of facial activity in the video recordings and ultrasonic markers.

The following parameters were computed: (1) frequency of laughing (number of laughing reactions to the sketch related to its length, $\mathrm{n} / \mathrm{min}$ movie); (2) initial velocity (IV, $\mathrm{mm} / \mathrm{s}$ ) of the ultrasonic markers at the beginning of laughing (mean slope through the start and maximum point of the correspondent movement based on three recordings); (3) emotional reaction time [ERT, time in seconds between a funny stimulus in the movie and laughing (average onset of correspondent movements of the mouth angles based on five humorous stimuli)].

\section{Statistical Analysis}

The above-mentioned variables were imported into the statistical program SPSS for Windows (version 11.5) and analyzed. In the present study, the relationships between parameters of facial 
activity and personality measures were assessed by SpearmanBrown correlation coefficients in view of the ordinal scale level of personality measures. Using partial correlation coefficients, the influence of possible moderator variables (like age) was controlled for, if necessary.

For statistical analysis, apart from laughing frequency and personality measures only IV and ERT of the right side were considered because all subjects were right-handed and association between left- and right-sided IV and ERT was strong (IV of the mouth angle markers: $\mathrm{r}=0.84 ; \mathrm{p} \leq 0.001 ; \mathrm{IV}$ of the eye markers: $\mathrm{r}=0.70 ; \mathrm{p} \leq 0.001 ;$ ERT: $\mathrm{r}=0.91 ; \mathrm{p} \leq 0.001)$.

The significance level was alpha-adjusted and set at 0.0025 $(=0.05 / 20)$.

\section{Results}

Regarding the NEO-FFI data, the mean score on Neuroticism (1.60) was average. All other personality dimensions ranged above-average $(>2.0)$. The highest scale scores were found for Openness to Experience (table 1). Overall, the NEO-FFI scores of the 46 participants were quite comparable with the correspondent scores of a German normative population (2,112 participants [21]). However, Agreeableness scores seem to be clearly elevated in our sample, as compared to the normatives. The score differences amounted to more than half of the standard deviation (table 1).

IV of involuntary (laughing) movements of the right and the left corner of the mouth was positively correlated with openness to experience (rho $\geq 0.32$; $\mathrm{p} \leq 0.03$, table 2). Higher IV of 'laughing' movements of the right medial inferior rim of the eye was associated with higher scores on Neuroticism (rho $=0.36, \mathrm{p}=0.03$ ) and Openness to Experience (rho $=0.41, \mathrm{p}=0.01)$. However, controlling for the significant influence of age on Openness to Experience as well as IV of the above-mentioned facial movements leads to a markedly lower correlation $(\mathrm{r}=$ $0.22, \mathrm{p}=0.20$ ).

The higher the SSS total scores in healthy volunteers, the higher was their IV of involuntary movements ("laughing') of the mouth angles (rho $\geq 0.33, \mathrm{p} \leq 0.03$, table 3 ). However, the marked positive correlation between total SSS scores and IV of 'laughing' movements of the right inferior rim of the eye (rho $=0.46, \mathrm{p}=0.006)$ vanishes if the effects of age are controlled for $(r=0.22, p=0.21)$.

The SSS dimension Thrill and Adventure Seeking was positively associated with IV of laughing-related movements of the right mouth angle (rho $=0.33, p=0.03)$ and the right inferior rim of the eye ( $r h o=0.34, p=0.05$ ) as well as laughing frequency ( $\mathrm{rho}=0.42, \mathrm{p}=0.006$ ); however, after accounting for the effects of age, the clear cor-
Table 1. Mean \pm SD of personality dimension scores in study subjects $(n=46)$ and normatives

\begin{tabular}{lll}
\hline Personality dimensions & Study subjects & Normatives \\
\hline SSS & & \\
Boredom Susceptibility & & - \\
$\quad$ Men & $4.84 \pm 1.89$ & $4.0 \pm 1.8$ \\
$\quad$ Women & $3.78 \pm 1.59$ & $3.7 \pm 1.9$ \\
\hline Disinhibition & & \\
$\quad$ Men & $4.32 \pm 2.06$ & $4.2 \pm 2.4$ \\
$\quad$ Women & $3.17 \pm 2.15$ & $3.2 \pm 2.1$ \\
\hline Experience Seeking & & \\
$\quad$ Men & $7.37 \pm 2.43$ & $5.7 \pm 2.1$ \\
$\quad$ Women & $6.30 \pm 2.30$ & $5.6 \pm 1.9$ \\
\hline Thrill and Adventure Seeking & & \\
$\quad$ Men & $5.47 \pm 2.74$ & $5.9 \pm 2.8$ \\
$\quad$ Women & $3.39 \pm 2.81$ & $4.4 \pm 2.6$ \\
\hline NEO-FFI & & \\
Neuroticism & & \\
Extraversion & $1.60 \pm 0.60$ & $1.84 \pm 0.70$ \\
Openness to Experience & $2.46 \pm 0.48$ & $2.36 \pm 0.57$ \\
Agreeableness & $2.85 \pm 0.45$ & $2.71 \pm 0.52$ \\
Conscientiousness & $2.76 \pm 0.41$ & $2.44 \pm 0.49$ \\
\hline & $2.60 \pm 0.48$ & $2.53 \pm 0.63$ \\
\hline
\end{tabular}

a The German population consisted of 1,526 subjects taken from Beauducel et al. [17].

b The German population consisted of 2,112 subjects taken from Borkenau and Ostendorf [21].

relation between Thrill and Adventure Seeking and IV of involuntary movements of the right eye marker does not exist any more $(\mathrm{r}=0.13, \mathrm{p}=0.46)$.

Instead, there was a higher positive correlation between Boredom Susceptibility and IV of involuntary movements of the inferior rim of the left eye during laughing (rho $=0.34, \mathrm{p}=0.05$ ). Since the influence of potential moderator variables (like age) was low, no partial correlation coefficient was computed for this association. Experience Seeking was only markedly correlated with IV of 'laughing' movements of the left mouth angle $($ rho $=0.31, p=0.05)$.

\section{Discussion}

The main results of the present study can be summarized as follows: Openness to Experience is positively associated with IV of 'laughing' movements of the mouth corners; similarly, sensation seeking with movements of 
Table 2. Spearman-Brown correlation coefficients between facial parameters and the personality dimensions on the NEO-FFI among 46 healthy subjects

\begin{tabular}{|c|c|c|c|c|c|c|}
\hline \multirow[t]{2}{*}{ Facial parameters } & \multirow[t]{2}{*}{ Mean $\pm \mathrm{SD}$} & \multicolumn{5}{|c|}{ Spearman-Brown correlation coefficients } \\
\hline & & NEURO & EXTRA & OPENNESS & AGREE & $\mathrm{CON}$ \\
\hline Initial velocity, right side & - & - & - & - & - & - \\
\hline Mouth angle marker, laughing & $7.90 \pm 5.33$ & -0.05 & 0.09 & $0.32^{*}$ & -0.13 & 0.13 \\
\hline Eye marker, laughing & $4.75 \pm 2.65$ & $0.36^{*}$ & 0.09 & $0.41^{*}$ & -0.19 & -0.07 \\
\hline Emotional reaction time, right side & $1.32 \pm 0.60$ & -0.10 & -0.16 & 0.02 & -0.14 & 0.04 \\
\hline Laughing frequency & $22.98 \pm 10.08$ & -0.19 & 0.14 & 0.28 & -0.02 & 0.22 \\
\hline
\end{tabular}

NEURO = Neuroticism; EXTRA = Extraversion; OPENNESS = Openness to Experience; AGREE = Agreeableness; CON $=$ Conscientiousness. ${ }^{*} \mathrm{p}<0.05$.

Table 3. Spearman-Brown correlation coefficients between facial parameters and the personality dimensions on the SSS among 46 healthy subjects

\begin{tabular}{llllll}
\hline Facial parameters & BORE & DIS & EXP & THRILL & GENERAL \\
\hline Initial velocity, right side & - & - & - & - & - \\
Mouth angle marker, laughing & 0.21 & 0.18 & 0.30 & $0.33^{*}$ & $0.33^{*}$ \\
Eye marker, laughing & 0.33 & 0.28 & 0.27 & $0.34^{*}$ & $0.46^{* *}$ \\
Emotional reaction time, right side & -0.08 & 0.16 & 0.10 & 0.22 & 0.13 \\
Laughing frequency & -0.20 & 0.23 & 0.19 & $0.42^{* *}$ & 0.30 \\
\hline
\end{tabular}

BORE = Boredom Susceptibility; DIS = Disinhibition; EXP = Experience Seeking; THRILL $=$ Thrill and Adventure Seeking; GENERAL $=$ total score in the SSS [14]. ${ }^{*} \mathrm{p}<0.05 ;{ }^{* *} \mathrm{p}<0.01$.

the mouth corners during 'sketch-induced' laughing. Higher Neuroticism scores are associated with higher IV of movements of the medial inferior rim of the right eye during laughing. The other personality dimensions are not related to IV of laughing. ERT is neither associated with sensation seeking nor personality dimensions assessed by the NEO-FFI. Laughing frequency is only related to Thrill and Adventure Seeking. It must be emphasized that the above-mentioned positive associations were statistically significant at the 5\% level, but failed the alpha-adjusted significance level $(\alpha=0.0025)$. Therefore, they must be regarded with much caution.

Regarding Openness to Experience, this tendency was found to be weakly associated with faster execution of adequate facial reactions to humorous stimuli. These reactions were more pronounced in the mouth corner region than at the middle inferior rims of the eyes [correlations with the IV of the eye markers failed the (nonadjusted) significance level (5\%)]. Therefore, Openness to
Experience seems to go along with faster emotionally induced activation of the zygomatic major and minor, risorius and depressor anguli oris muscles, as compared to activation of the orbicularis oculi muscle.

In contrast, the association of Extraversion and facial parameters was not significant at all at the 5\% level. This lack of significant correlations seems to contradict previous findings suggesting a close association between Extraversion and the ability of 'spontaneous' encoding of emotional experience. In this context, it must be seen that having an emotion like joy is not a sufficient condition for a correspondent facial expression since display rules and social motives are relevant parts in facial expression that are distinct from action tendencies as responses to presented material. Usually, the facial expression of emotions is facilitated by the real presence of another person and otherwise repressed in a viewing situation [23].

It is possible that the association between Extraversion and facial expression of humor in our experiment would 
have been much closer in the case of introducing an interaction task (like telling jokes by a confederate) or a manipulation procedure using alcohol [24].

Regarding sensation seeking, it was associated with faster movements of the mouth corner region during sketch-related laughing. High sensation seeking has been conceptualized as an autoregulative reaction to low tonic activity of an activation system which has not been clearly specified. Following this concept [15], sensation seekers need to create for themselves stimulating environmental conditions in order to elevate their activation level to a higher range. In line with this concept, IV of facial movements during laughing (especially on the right side) and laughing frequency were associated with higher scores on Thrill and Adventure Seeking, indicating higher susceptibility regarding (activating) humorous stimuli.

Boredom Susceptibility - similar to the NEO-FFI factor Neuroticism - was mainly associated with IV of movements of the eye markers during laughing, Experience Seeking with IV of movements of the ultrasonic markers in the mouth corner region. Disinhibition was not associated with facial activity.

In contrast to IV of facial activity, ERT was not correlated with sensation seeking at all. Therefore, sensation seeking does not seem to influence the transformation of the feeling 'funny' into the motor reaction 'laughing' in a significant way. The morphological substrate of this transformation is postulated to be the nucleus accumbens, the so-called limbic-motor interface [25]. Since starting of the above-mentioned motor programs seems to be independent from sensation seeking as well as personality dimensions measured by the NEO-FFI, it is not very likely that the limbic-motor interface plays an important role in the neurobiology of personality.

The positive association between IV of laughing and action-related personality dimensions (Openness to Experience, sensation seeking) being significant at the 5\% level, but failing the alpha-adjusted significance level suggests that these personality factors might play a role in the modulation of the expression of laughter by activating an 'emotionally driven' neuronal pathway which involves limbic structures (especially the amygdala), thalamic, hypothalamic and subthalamic areas (including basal ganglia) as well as the dorsal/tegmental brainstem [26]. The output of this system consists of the nervus facialis and special facial muscles innervating the mouth corner region and the middle inferior rims of the eyes.

Our (uncorrected) finding that speed of facial movements during laughing was elevated in participants with higher scores on sensation seeking may reflect an inverse association between speed of laughing and serotonergic activity because persons with strong sensation seeking were characterized by low concentrations of 5-hydroxyindole acetic acid (5-HIAA), the main metabolite of serotonin, in the liquor [e.g., ref. 27]. Moreover, in a study on 40 healthy volunteers [28], sensation seeking was positively associated with a high loudness dependency of auditory evoked potentials in the primary auditory cortex, reflecting low serotonergic activation of this brain region [see also ref. 29]. Therefore, emotionally induced facial expressions and action-related personality styles (sensation seeking, Openness to Experience) might be modulated by the serotonergic brain system.

In conclusion, our study suggests that facial expression is linked to sensation seeking and related personality styles. However, it should be underlined that the results of the present pilot study are preliminary because our sample was rather small and not representative because mainly subjects with quite high educational level were investigated and elderly patients were underrepresented in the sample. Moreover, we used a rather idiosyncratic method. The main advantage of this approach may be that it combines exact measurement of motor data and global assessment of the facial expression of emotions (by video). Nevertheless, it needs validation. In this context, it would be fruitful to combine the interval-scaled quantitative aspects of facial expression of emotions as provided by our kinematical approach (e.g., combinations of velocities or quantitative specification of marker positions) with the rating data of the (rather static) Facial Action Coding System (FACS) involving all relevant elements (action units 6, 12 and 25) of the facial correlative of joy [30]. In addition, our study involved the calculation of a larger number of correlations, thus increasing the probability of type I errors. Therefore, replication of the reported findings will be essential. 


\section{References}

1 Darwin C: The Expression of the Emotions in Man and Animals. London, Albemarle, 1872.

2 Magai C, Cohen CI, Culver C, Gomberg D, Malatesta C: Relation between premorbid personality and patterns of emotion expression in mid- to late-stage dementia. Int J Geriatr Psychiatry 1997;12:1092-1099.

3 Niedenthal PM, Brauer M, Robin L, InnesKer AH: Adult attachment and the perception of facial expression of emotion. J Pers Soc Psychol 2002;82:419-433.

4 Buck R: The Communication of Emotion. New York, Guilford, 1984.

5 Friedman HS, DiMatteo MR, Taranta A: The relationship between individual differences in nonverbal expressiveness and factors of personality and social interaction. J Res Pers $1980 ; 14: 351-364$

6 Friedman HS, Riggio RE, Segall DO: Personality and the enactment of emotion. J Nonverb Behav 1980;5:35-48.

7 Juckel G, Polzer U: Fine analysis of abnormal facial expressions in chronic schizophrenic patients - a pilot study. Germ J Psychiatry 1998;1:6-9.

8 Juckel G, Prässl A, Froschmayr S, Mavrogiorgou P, Tigges P, Möller HJ, Hegerl U: «Im Gesicht lesen lernen»: Mimikanalyse schizophrener Patienten; in Machleidt W, Haltenhof H, Garlipp P (eds): Schizophrenie - eine affektive Erkrankung? Stuttgart, Schattauer, 1999, pp 127-134.

9 Padberg F, Juckel G, Prässl A, Zwanzger P, Mavrogiorgou P, Hegerl U, Hampel H, Möller HJ: Prefrontal cortex modulation of mood and emotionally induced facial expressions: a transcranial magnetic stimulation study. J Neuropsychiatry Clin Neurosci 2001;13:206-212.
10 Mergl R, Mavrogiorgou P, Hegerl U, Juckel $\mathrm{G}$ : Kinematical analysis of emotionally induced facial expressions: a novel tool to investigate hypomimia in patients suffering from depression. JNNP 2005;76:138-140.

11 Mergl R, Vogel M, Mavrogiorgou P, Göbel C, Zaudig M, Hegerl U, Juckel G: Kinematical analysis of emotionally induced facial expressions in patients with obsessive-compulsive disorder. Psychol Med 2003;33:14531462 .

12 World Medical Association: World Medical Association declaration of Helsinki: Recommendations guiding physicians in biomedical research involving human subjects. JAMA 1997;277:925-926.

13 Dilling H, Mombour W, Schmidt MH: Internationale Klassifikation psychischer Störungen ICD-10, Aufl 2. Bern, Huber, 1993, Kap V.

14 Zuckerman M: Sensation seeking; in Hare RD, Schalling D (eds): Psychopathic Behavior: Approaches to Research. New York, Wiley \& Sons, 1978, pp 165-185.

15 Zuckerman M: Are you a risk taker? Psychol Today 2000;33:52-56.

16 Zuckerman M: Dimensions of sensation seeking. J Consult Clin Psychol 1971;36:4552.

17 Beauducel A, Strobel A, Brocke B: Psychometrische Eigenschaften und Normen einer deutschsprachigen Fassung der SensationSeeking-Skalen, Form V. Diagnostica 2003; 49:61-72.

18 Borkenau P, Ostendorf F: Ein Fragebogen zur Erfassung fünf robuster Persönlichkeitsfaktoren. Diagnostica 1991;37:29-41.

19 McCrae RR, Costa PT Jr: Validation of the five-factor model of personality across instruments and observers. J Pers Soc Psychol 1987;52:81-90.

20 John OP, Srivastava S: The Big Five trait taxonomy: history, measurement, and theoretical perspectives; in Pervin LA, John OP (eds): Handbook of Personality, ed 2. New York, Guilford, 1999, pp 102-138.
21 Borkenau P, Ostendorf F: NEO-Fünf-Faktoren-Inventar (NEO-FFI) nach Costa und McCrae. Göttingen, Hogrefe, 1993.

22 Hermsdörfer J, Wack S, Mai N, Marquardt C: Dreidimensionale Bewegungsmessung zur Analyse der Handfunktion. München, Entwicklungsgruppe Klinische Neuropsychologie (EKN), 1996.

23 Parkinson B: Do facial movements express emotions or communicate motives? Pers Soc Psychol Rev 2005;9:278-311.

24 Ruch W: Extraversion, alcohol, and enjoyment. Personality Ind Diff 1994;16:89-102.

25 Mogenson GJ, Johnes DL, Yim CC: From motivation to action: functional interface between the limbic system and the motor system. Prog Neurobiol 1980;14:69-97.

26 Wild B, Rodden FA, Grodd W, Ruch W: Neural correlates of laughter and humour. Brain 2003;126:2121-2138.

27 Brown GL, Linnoila MI: CSF serotonin metabolite (5-HIAA) studies in depression, impulsivity, and violence. J Clin Psychiatry 1990;51(suppl 4):31-41.

28 Hegerl U, Gallinat J, Mrowinski D: Sensory cortical processing and the biological basis of personality. Biol Psychiatry 1995;37:467472 .

29 Hegerl U, Juckel G: Intensity dependency of auditory evoked potentials as indicator of central serotonergic neurotransmission: a new hypothesis. Biol Psychiatry 1993;33: 173-187.

30 Frank MG, Ekman P, Friesen WV: Behavioral markers and recognizability of the smile of enjoyment. J Pers Soc Psychol 1993;64:8393. 